\title{
Transitions at Tobacco Control
}

\section{Ruth Malone}

This first 2009 issue of Tobacco Control marks a time of multiple transitions for the journal, and this editorial highlights four important changes. First, Simon Chapman, long-time editor (and deputy editor under the founding editor Ron Davis, whose exceptional leadership contributions to the journal and the field are eulogised in this issue) is stepping down. I undertake my tenure as Simon's replacement with feelings that vacillate between quaking trepidation and giddy exhilaration, depending upon how late the hour and how elevated the piles on my desk. It is impossible to overstate Simon's contributions to Tobacco Control, and no one who steps into this role could match his trenchant combination of savvy strategic thinking, vision and razor-edged, witty editorial writing.

However, the good news is that while Simon is stepping aside as editor, he is not lost to the journal. In this issue, we are delighted to announce that Tobacco Control is the recipient of a substantial Bloomberg and Gates Foundation grant, awarded for the purpose of expanding journal content pertaining to tobacco control research, advocacy and policy in low and middle-income countries (LMICs). This expansion has been a long-time vision of Simon's, and with the ongoing work of implementing the Framework Convention on Tobacco Control, it should also be a valuable tool for furthering tobacco control learning-

Correspondence to: Professor Ruth E Malone,

Department of Social and Behavioral Sciences, 3333

California Street Suite 455, University of California San

Francisco, San Francisco, CA 94118, USA; ruth.

malone@ucsf.edu in all directions. Simon has generously agreed to accept a position as commissioning editor for LMICs and will take the lead on developing this incredibly exciting initiative, about which you will be seeing and hearing much more in future issues.

Third, observant readers will notice some changes to the journal's masthead, as I exercise the new editor's traditional prerogative of restructuring the editorial team and some of the topic areas. In doing so, I sought both to retain some continuity and to bring in some fresh perspectives, including adding an assistant editor for new media to help the editorial board consider how best to engage with emerging media forms and technological innovations. I hope that the changes will enhance the journal's focus on communicating thought-provoking ideas while publishing the very best work (research, analysis and news reporting) on tobacco control at the population and policy levels. Everyone in tobacco control owes gratitude to those who have served the journal for many years, and we honour that service. The journal also depends upon the support of the entire tobacco control community, including those who submit their papers, review for the journal, cite the papers published in it, advise the editorial team, contribute ideas and respond to published material, either through letters or through our Rapid Response function.

This leads me to a last change, one that I hope others will find as exciting as I do: a new "Perspectives" feature that we hope to run at least every other issue, highlighting debates about key tobacco control questions. In this first round, long-time tobacco control advocate and law professor Richard Daynard argues for what has long been regarded as unthinkable - a phased elimination of cigarettes. Peter Hanauer, another long-time advocate for smoke-free air, argues against "prohibition". Following their debate, you can review a set of invited responses from others in the movement around the world-invited with no foreknowledge of their likely content, I hasten to add. The debate's fundamental question, I think, represents one of the ultimate paradoxes tobacco control advocates continue to live with: almost all can agree that cigarettes, as the most deadly consumer product ever made, really shouldn't be on the marketbut we can't agree that stopping their sale should be a tobacco control priority. What do you think? We hope you will weigh in on these issues in a rapid response, and if you have ideas for other possible debates, I'd be happy to entertain suggestions for future contributions that will keep the conversations going. Healthy debate within a context of mutual respect can, I believe, stretch our thinking beyond the taken-for-granted.

The journal has grown since its inception in 1992 to be one of the most influential public health journals, with a 2007 impact factor (an important measurement of a journal's reach in the field) of 3.277. Continuing to grow the journal and keep it relevant for tobacco control scientists, practitioners and advocates all over the world will involve more than the work of a new editor learning the ropes. Each of you reading this-well, excepting the inevitable tobacco industry grunts who follow our work in order to undermine it-helps make the journal so outstanding. It is my goal to involve and engage even more of you, and to feature more of your path-breaking work in public health and tobacco control policy.

\section{Competing interests: None.}

Tobacco Control 2009;18:1. doi:10.1136/tc.2008.028696 